Infrastructure Assurance Analysis Project

\title{
Electrical Substation \\ Service-Area Estimation Using Cellular Automata: \\ An Initial Report
}

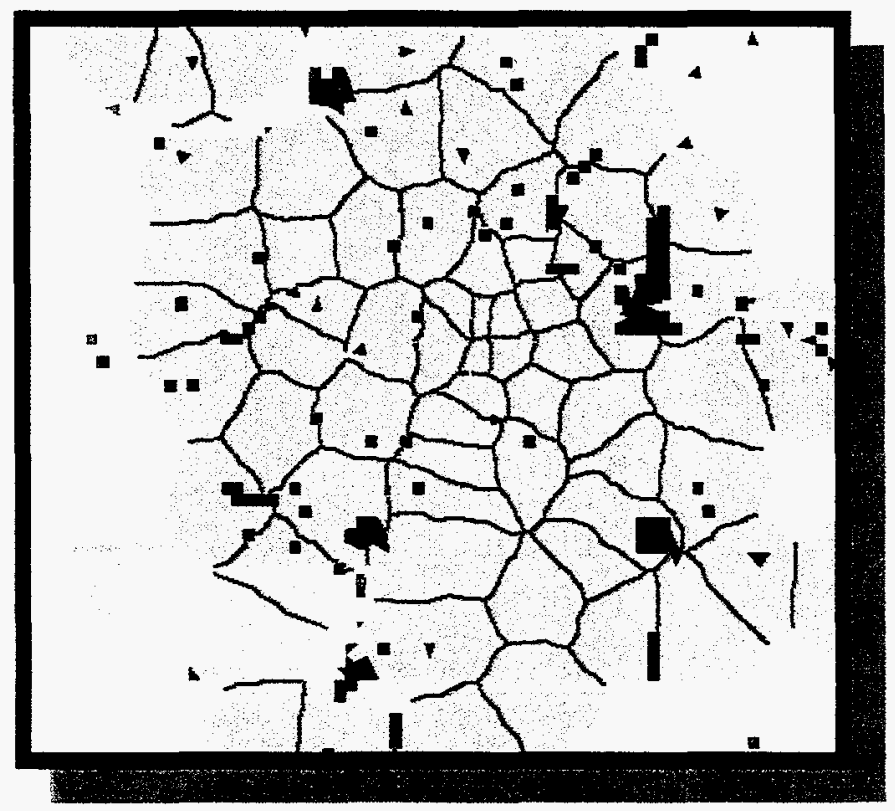

\section{John W. Fenwick \\ L. Jonathan Dowell}

LA-UR-98-2803

DISTRIOUTION OF THS DOCURENT IS UNMIMTED July 1998

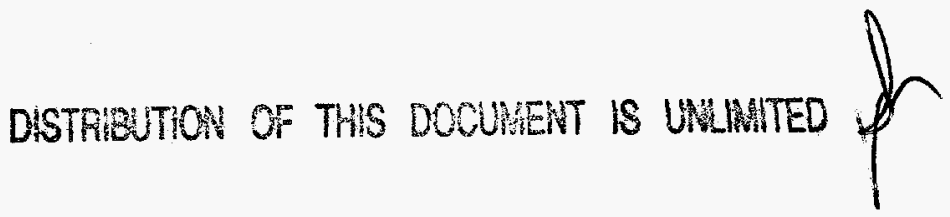

Los Alamos National Laboratory is operated by the University of California for the United States Department of Energy under contract W-7405-ENG-36. 


\section{DISCLAIMER}

This report was prepared as an account of work sponsored by an agency of the United States Government. Neither the United States Governmeat nor any agency thereof, nor any of their employees, makes any warranty, express or implied, or assumes any legal liability or responsibility for the acouracy, completeness, or usefulness of any information, apparatus, produce, or process dicelosed, or represents that its use would not infringe privately owned rights. Reference herein to any spe. cific commercial product, process, or service by trade name, trademart, inanufacturer, or otherwise does not necessarily constitute or imply its endorsemeat, recommendation, or favoring by the United States Government or any agency thereof. The views and opinions of authors expressed herein do not necessarily state or rellect those of the United States Government or any agency thereof. 


\section{DISCLAIMER}

Portions of this document may be illegible in electronic image products. Images are produced from the best available original document. 


\title{
Electrical Substation \\ Service-Area Estimation \\ Using Cellular Automata: \\ An Initial Report
}

John W. Fenwick

L. Jonathan Dowell

LA-UR-98-2803

July 1998

\begin{abstract}
- The service areas for electric power substations can be estimated using a Cellular Automata (CA) model.

- The CA model is a discrete, iterative process whereby substations 'acquire' service area by claiming neighboring cells. The service area expands from a substation until a neighboring substation service area is met or the substation's total capacity or other consfraints are reached.

- The CA-model output is dependent on the rule set that defines cell interactions. The rule set is based on a hierarchy of quantitative metrics that represent real-world factors such as land use and population density. Together, the metrics determine the rate of cell acquisition and the upper bound for service area size.

- Assessing the CA-model accuracy requires comparisons to actual service areas. These actual service areas can be extracted from distribution maps.

- Quantitative assessment of the CA-model accuracy can be accomplished by a number of methods. Some are as simple as finding the percentage of cells predicted correctly, while others assess a penalty based on the distance from an incorrectly predicted cell to its correct service area.

- This is an initial report of a work in progress.
\end{abstract}




\section{Electrical Substation Service-Area Modeling Using Cellular Automata: An Initial Report}

The Infrastructure Analysis Assurance Project evaluates vulnerabilities in the U.S. electric-power infrastructure.

Substations form the hubs of electric-power distribution.

A model is needed to estimate substation service areas.

\section{Introduction / Background}

The Infrastructure Assurance Analysis Project (IAAP) at Los Alamos National Laboratory evaluates vulnerabilities in the national electric-power infrastructure. The evaluation analyzes the cause-and-effect relationship between critical electrical components and loss of electric service.

Electric power in the United States is produced at centralized power plants and then delivered to a region through an interconnected transmission and distribution system. Electricity generated in power plants is transformed into very high voltages (66-765 kV for long-distance transmission to reduce power losses due to line length [1]. Transmission lines terminate in substations, where the voltage is reduced to the distribution voltage. Substations form the hubs of radial electric-power distribution systems.

Data for substations are publicly available through annual Federal Energy Regulatory Commission filings. However, power companies are not obliged to provide more-detailed information. Absent from the filings are the substations' service areas; therefore, the geographic area served by each substation is unknown [2]. Knowing substation service areas is important for IAAP infrastructure analysis. A model able to estimate accurately substation service areas from publicly available information is needed.

This report describes the estimation of substations' service areas by a Cellular Automata model. The report describes the methodology, accuracy, and uncertainty of the method. Development of this method is a work in progress, and this report describes the status of this work at the time of the writing. 
The Voronoi method uses weighted distances to estimate substation service areas.

The Voronoi method of substation service-area estimation proved unsatisfactory.

A Cellular Automata model is a discrete, iterative process.

The state of each cell depends on its neighbors.

The Game of Life is the most easily understood $C A$ model, and forms the foundation for the servicearea estimator.

\section{Methodology}

One possibility for estimating substations' service areas is the Voronoi method of weighted distances [2]. This method is based on known substation load and distance from the substations. It produces a geometric partitioning of the area around substations.

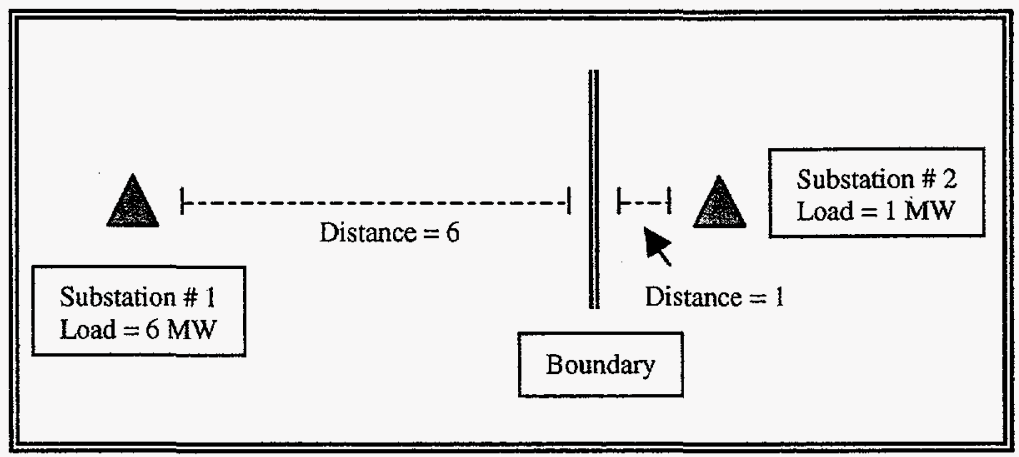

Figure 1. Voronoi Method

The Voronoi method is limited in its ability to include terrain features and land use in the estimation of service territories. Also, it is a definitive predictive method, limited in ability to represent uncertainty. These limitations encouraged the development of alternative methods.

Another, more intuitive method for determining substations' service areas uses Cellular Automata (CA). A CA model is a discrete, iterative process where many objects of a system interact with each other. CA space consists of a discrete, regular lattice, and each cell in the CA lattice can have one of a finite number of states [3]. The state of each cell depends on the states of its immediate neighbors (adjacent cells) and the rule set that defines the cell interactions. The CA evolve in a succession of time steps, with each time step updating the entire lattice simultaneously.

The first, best known, and most easily understood CA model is the Game of Life, created by John Conway [4]. It uses a two-dimensional Boolean lattice, with each cell being either alive or dead. The rule set for the Game of Life determines when a cell is born, remains alive, or dies. The rule set is as follows:

- $\quad$ Any cell with three living neighbor cells remains alive or is born.

- Any living cell with two living neighbors remains alive.

- All other cells remain dead or die.

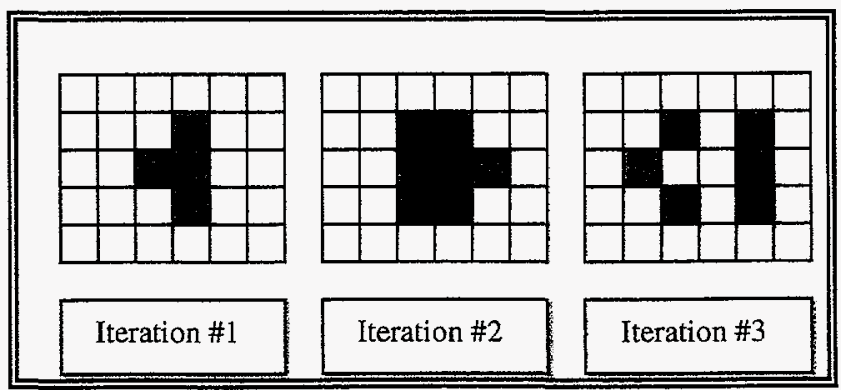

Figure 2. Game of Life 
As the CA evolve, each substations' cells acquire the cells that surround them. The cells acquired become the substation's service area.
The rate, number, and type of cells that a substation acquires are all dependent on the CA rule set.

The rule-set metrics determine the rate of purchase and the total number of cells purchased by each substation.

Rate of purchase is a function of substation purchasing power and cell desirability.

Substations with more load acquire cells faster.

Land types (residential, commercial, industrial) affect cell desirability.
Solving for substation service areas applies the fundamental concepts of Conway's Game of Life. The service area CA divide a map into a discrete number of cells, each of which represent a service-area portion. Each substation is then placed in its geographic position. As the CA evolve, each substation acquires the cells that surround it, much like a growing organism in the Game of Life. The cells that each substation acquires constitute its service area.

The process of acquiring neighboring cells is most easily understood using money as an analogy. Acquisition of a cell means that it is 'purchased' by its neighbor. The cells at the edges of a substation service area purchase neighboring unowned cells. Cells that are contested by multiple substations become the boundary cells, with the boundary thickness corresponding to the level of uncertainty in the model.

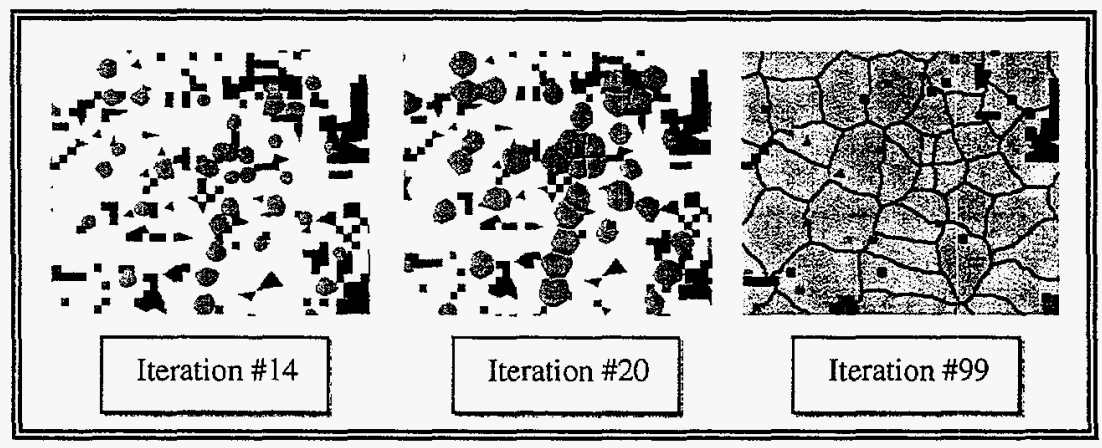

Figure 3. Service Area CA Model

The rate, number, and type of cells that a substation acquires are all dependent on the CA rule set. Therefore, the rule set determines the model output and resulting accuracy. The rule set uses several metrics; quantitative values that describe imprecise, real-world factors. The metrics ultimately determine the overall rate of purchase and the total number of cells purchased by each substation.

The rule set for service-area purchasing requires a number of metrics. Rate of purchase is a function of two factors, substation purchasing power and cell desirability. Purchasing power is the amount of money a cell can put down on its neighbor in one iferation. Substations with a higher total load have a higher purchasing power, and therefore grow at a faster rate.

The demands and characteristics that determine the cell desirability of the cells in the service area also affect the rate of purchase. Differing land types, such as commercial, residential, and agricultural zones, have significantly different electrical power revenues and expenses associated with them. For instance, industrial cells often only require a single distribution line into the cell, whereas residential cells need a complex network of wires and meters to provide electrical service. Maintenance and operation costs are therefore greater in residential areas. Prices charged per kilowatt hour also change depending on land type. The net result of differing expenses and revenue is unequal levels of profitability, and therefore of cell 
Roads have a high level of desirability because service areas expand faster along them.

Pre-CA smoothing for cell desirability accounts for unequally desirable neighboring cells.

Cells farther from the substation are less desirable due to maintenance costs and power losses.

Overall rate of purchase is determined by combining substation purchasing power and cell desirability.

An upper bound for substation service area size is needed because service areas cannot grow into infinity. desirability. Cells with a higher desirability are purchased at a higher rate, and thus zoning affects this metric.

One interesting example is how roads are incorporated into the CA. In reality, many distribution lines travel along major roads. Therefore, along roads are where service areas expand faster. The CA model accounts for this by giving road cells a high level of desirability.

In another example, a challenge arises when parking lots (low desirability) surround shopping malls (high desirability). By its nature, the owned cells only look at neighboring cells when purchasing. Therefore, the parking lot is seen and ignored on its own merits, even though it neighbors the high-value shopping mall. One solution to this problem is to introduce a pre-CA smoothing of cell desirability. Each cell's desirability then includes its neighbors' desirability as well as its own. This makes intuitive sense, as owning the parking lot is desirable solely because it gives access to the mall it neighbors. Through several iterations, neighbors at some distance can affect a cell's desirability.

Cell type is only one factor that influences cell desirability. Another factor is cell distance from the substation. Cells farther from the substation are less desirable because of maintenance costs and power losses caused by distribution-line lengths. The distance from the substation metric incorporates the operating voltage of the substation. Voltage is a factor because higher operating voltages produce less line losses. Therefore, cell desirability is a function of both cell type and distance from the substation, and reflects profitability.

The overall rate of purchase is determined by combining substation purchasing power and cell desirability into a single metric.

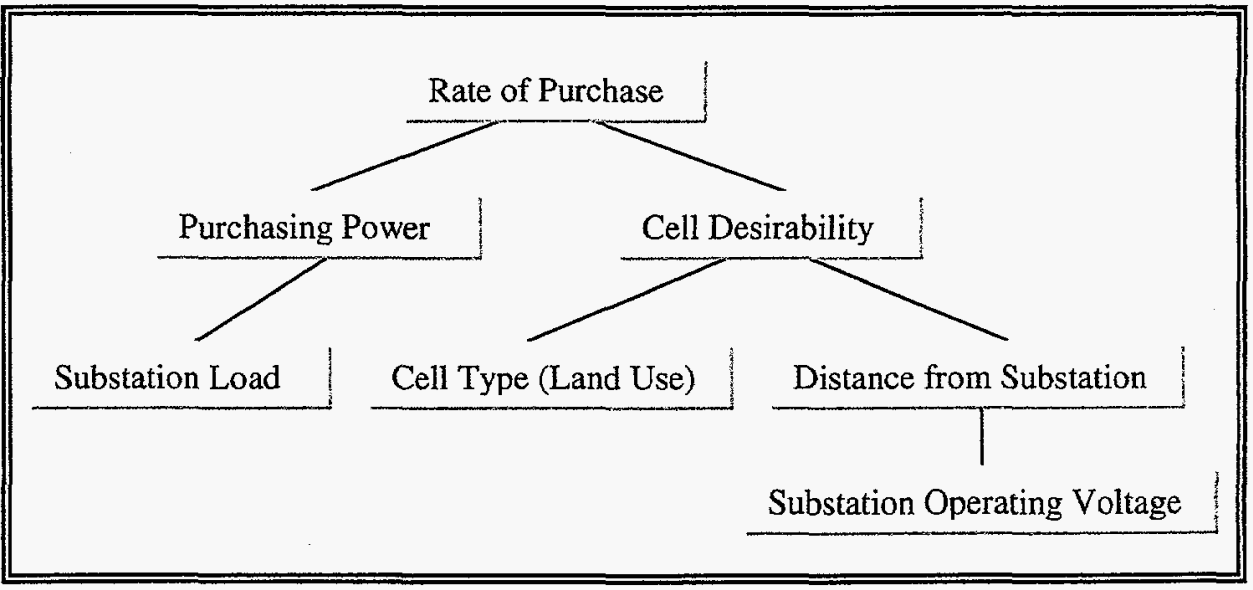

Figure 4. Factors for Rate-of-Purchase Metric

Another important rule for the service-area $C A$ is ensuring an upper bound for the size of a substation service area. Service areas for substations cannot grow into infinity; the service area cannot extend beyond the actual substation capacity [5]. By finding the average load per cell, the predicted load for the entire service area can be calculated. When the sum of cell 
Land type and population density affect the average lood per cell.

Estimation of a cell's contribution to peak load depends on time of day and day of the week.
The accuracy of the model is analyzed by comparing the predicted results to an actual service area map.

The method for determining service areas from these maps is imprecise at best. loads is equal to the substation capacity, the substation service area stops growing.

Determining the average load per cell involves isolating contributing factors. Land type plays an important role [6]. Residential areas consume different amounts of power per unit area than industrial zones. Population density is also a factor. Loads in urban residential areas are higher per unit area than in suburban or rural areas.

The load that can be served by a substation is bounded by the substation capacity. In general, the peak load at the substation will be a fraction of this capacity. When using substations' peak load to limit the substations' service areas, it is important to estimate the average load per cell for the time of day and day of the week at which the peak load occurred.

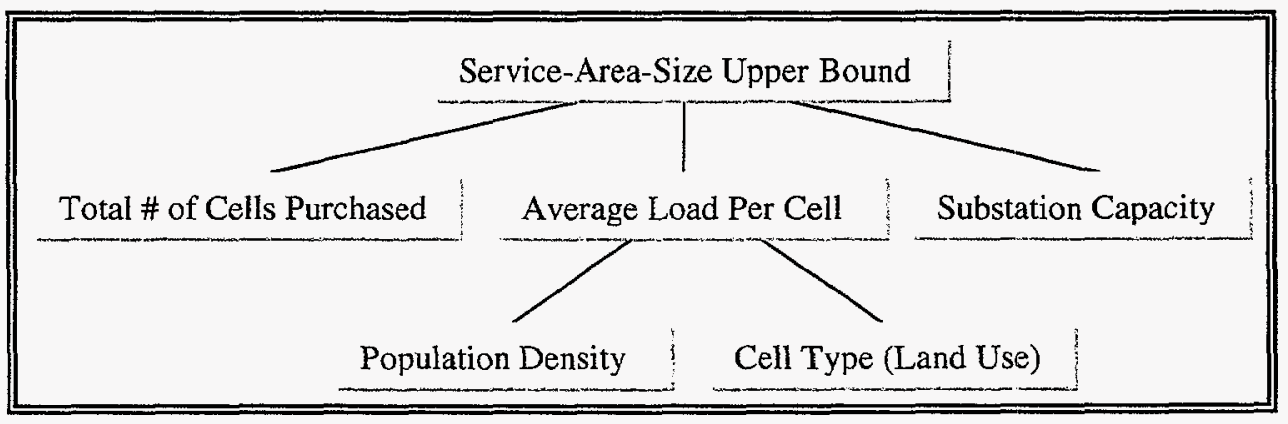

Figure 5. Factors for Service-Area-Size Upper Bound

\section{Accuracy Assessment}

\section{Actual Service-Area Construction}

Once the CA model estimates the substations' service areas, the accuracy of the model can be analyzed by comparing the prediction to an actual service-area map. This is challenging, for the absence of actual service-area maps is the reason for producing a service area model in the first place.

For the prototype under development, detailed electrical distribution maps for approximately $20 \%$ of the Denver metropolitan area provide a basis for the evaluation of the accuracy of the CA model. The method for determining service areas from these maps is imprecise at best and deserves further explanation. 
Connecting open switches on a distribution map determines service area boundaries.

Some distribution groups originating from different substations are linked without any open switches.
The electrical distribution maps of the Denver metropolitan area consist of main distribution lines overlaid on a street map. These distribution lines are loosely color-coded by group and connected in a grid by open and closed switches, sectionalizers, and reclosers. The following legend aids interpretation.

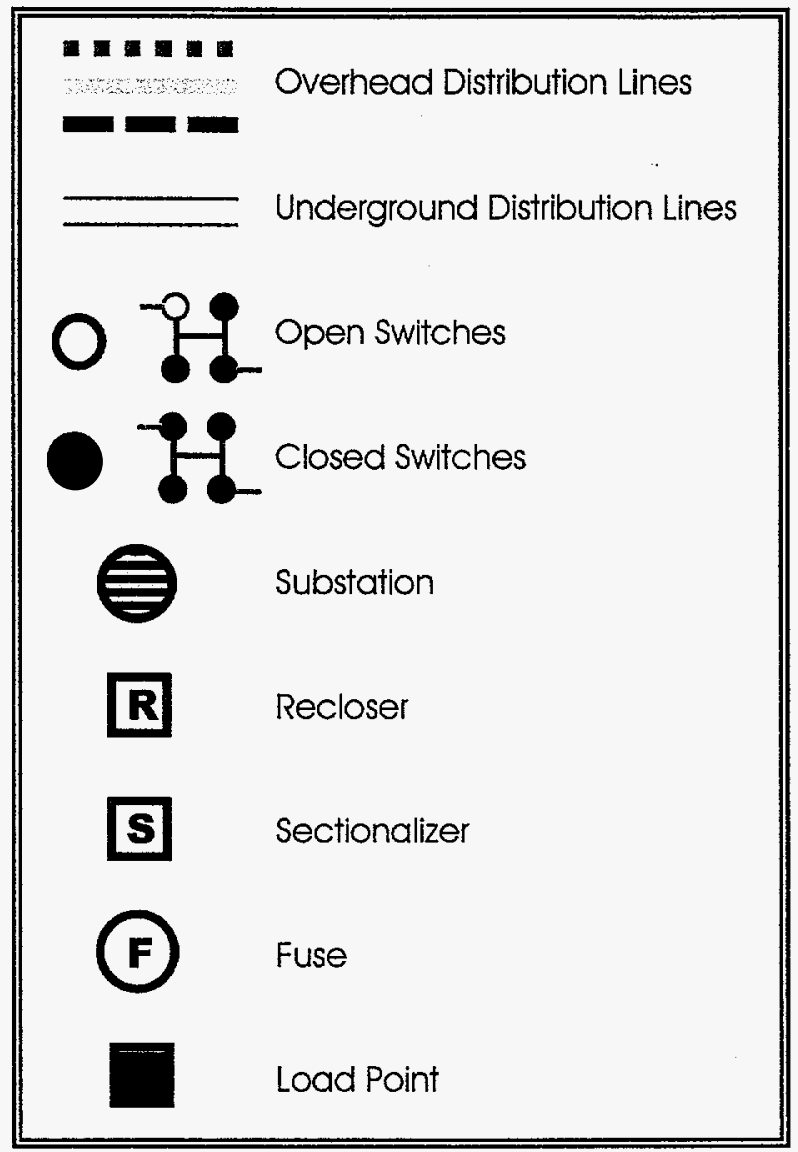

Figure 6. Denver Distribution-Map Legend

The overlapping and interconnected nature of urban electrical distribution makes identifying service areas from these maps an imprecise process. It is important to note that only the distribution groups are shown - the maps do not delineate house-by-house service. 'Polygoning' determines service area boundaries; connecting open switches between distribution groups [7]. However, some distribution groups originating from different substations are linked without any open switches. This makes determining where one service area ends and another begins impossible. 
Map borders hinder service area determination.
Latitude and longitudes of known locations serve as georeference points.

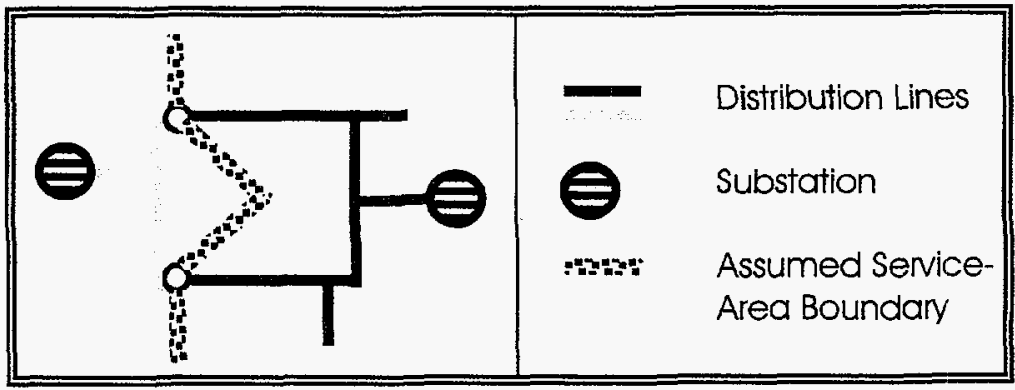

Figure 7. Defermination of Service-Area Boundary

The distribution groups shown on the map also do not cover the entire area shown on the map. The boundary between distribution groups is determined by bisecting the distance between the groups, an assumption that may or may not be appropriate. This bisection using distance takes various forms. For example, an area bordered on three sides by one distribution group and on one side by another requires creative partitioning.

Furthermore, the maps are not contiguous. Therefore, it is impossible to determine whether distribution groups originating from the map border are from a substation on the map, or from one off the map.

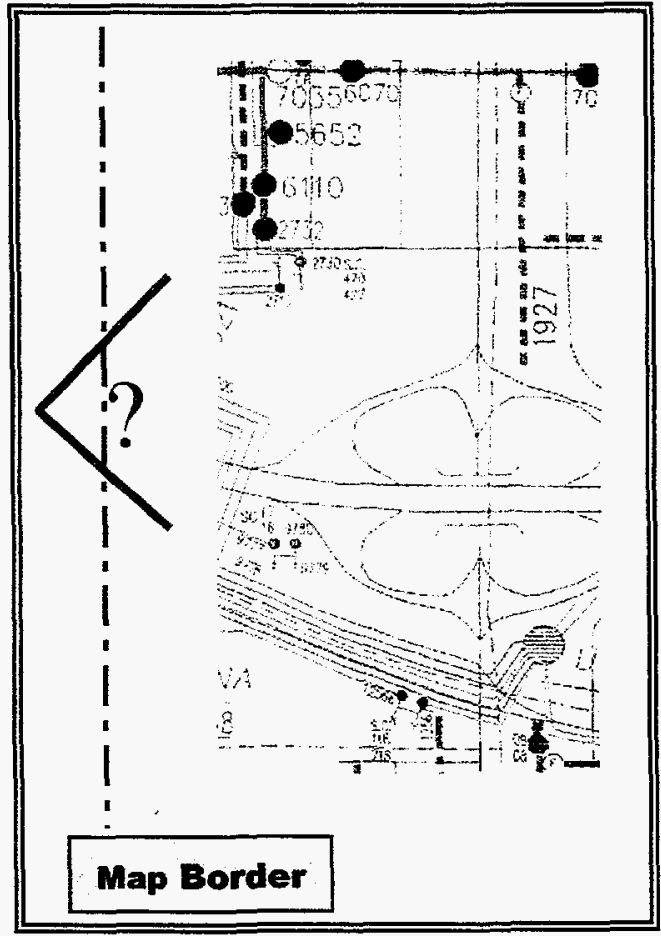

Figure 8. Service-Area Determination Map-Border Problem

After the service area boundaries are drawn by hand on black and white photocopies of the distribution maps, georeference points are added. Latitude and longitudes of known locations such as major intersections are then found using Street Atlas USA ${ }^{\circledast}$ 5.0. The digitizing surface is only $24 \times 28$ inches, 
The result of the digitizing process is service area boundaries compiled in ArcView ${ }^{\boxplus}$ shapefiles.

A variety of methods provides quantitative measures of the accuracy of the CA.

Percentage of service area correctly predicted is simple and intuitive.

Another method is assessing a penalty based on the cell's distance from the correct service area.

An advantage of the $C A$ model is the evaluation of certainty of the estimated service areas.

Ownership of the cells at borders between neighboring service areas is uncertain. so the larger maps need to be digitized in sections. Twelve georeference points are needed for each map to ensure that four points are present in each section to be digitized. The result of the digitizing process is service-area boundaries compiled in ArcView ${ }^{\circledast}$ shapefiles for the portion of Denver covered by the distribution maps.

\section{Model Vs. Actual Service Area Comparison}

The next step is comparing the estimated service area boundaries found by the CA model to the 'actual' boundaries found by map analysis. A variety of methods provide quantitative measures of the accuracy of the CA. The overall goal is to maximize the accuracy of the CA model by optimizing the metrics within the CA rule set.

The simplest way to evaluate accuracy is by finding the percentage of service area correctly estimated. In this method, the estimated service area is compared to the actual service area and each cell is evaluated for correctness.

Another, more descriptive measure of accuracy incorporates the magnitude of the estimation error. When a cell is estimated incorrectly, a penalty is assessed based on the cell's distance from the correct service area.

Quantitative accuracy assessment is important because the CA rule set then can be adjusted to maximize accuracy. One possible method for implementing this feedback is to make the CA rule set a genetic algorithm, allowing the rule sef to evolve to find the optimal solution.

\section{Uncertainty}

An advantage of the CA method over the Voronoi method is in the evaluation of uncertainties in the estimation of substations' service areas. Because the area being partitioned into service areas is first divided into individual cells, a likelihood of correct assignment of ownership can be evaluated for each cell. Consequently, the estimated service area for each substation can be further subdivided into a series of concentric rings of constant likelihood of service by that substation. This likelihood of service is useful in applying the CA result to the assessment of electrical service to a particular site where the substation serving that site is unknown beforehand.

In simplest application, the cells at the borders between the service areas of neighboring substations are "contested." That is, two or more substations in the CA model attempt to purchase these cells. There is then some uncertainty as to which of the candidate substations serves these cells. Similarly, there may be uncertainty of ownership of the cells that are adjacent to the border cells. 
The CA model can estimate certainty of ownership of each cell.
The CA model is a powerful and potentially accurate tool for estimating substations' service areas.

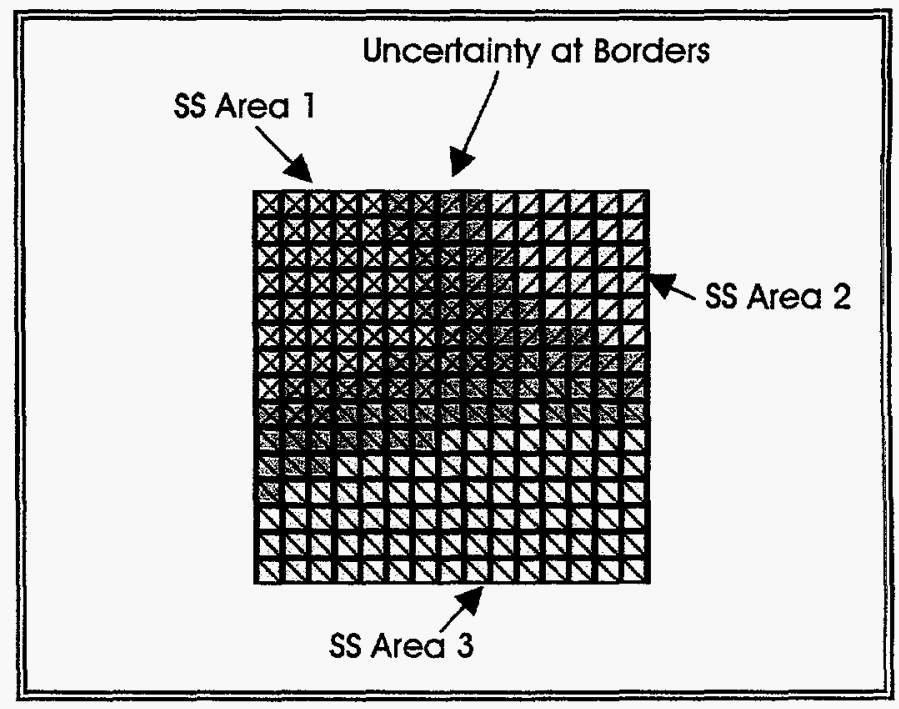

Figure 9. CA Estimates Uncertainties at Service-Area Borders

This approach can be expanded by assessing the likelihood of a cell being served by a substation at the time the cell is purchased by that substation in the CA model. Likelihood of ownership of a cell is a function of the distance between that cell and the substation claiming to own it (DX 1), between that cell and the neighboring competitive substations (DX 2), and between that cell and those competitors' owned borders at the time the cell is purchased (DX 3). Intuitively, a substation has a high likelihood of serving those cells close to it. A cell far from a substation is still likely to be served by that substation if the distance to other competitive substations is large. Uncertainty increases as cells approach the borders of service areas.

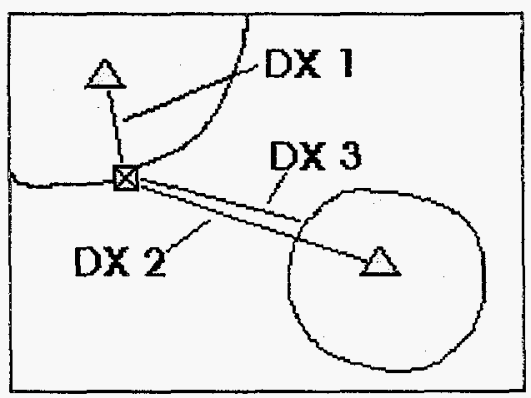

Figure 10. CA Estimates Likelihood of Ownership of Each Cell in Substation's Service Area

\section{Conclusions}

The Cellular Automata model is a powerful and potentially accurate tool for estimating substations' service areas. This report summarizes the status of this model as a tool development of this CA model is very much a work in progress. Refining the rule set through comprehensive comparison with actual service areas is important. Only then can the usefulness and limitations of the CA model be assessed. 


\section{References}

1. James J. Burke, Power Distribution Engineering: Fundamentals and Applications (Marcel Dekker, New York, 1994), Chap. 3.

2. Kevan Q. Newton and David E. Schirmer, "On the Methodology of Defining Substation Spheres of Influence Within an Electric Vehicle Project Framework," 1997 Environmental Systems Research Institute (ESRI) User Conference, Online, (http://www.esri.com/base/common/usercomp/proc97/PR OC97/abstract/a445.htm).

3. R. J. Gaylord and K. Nishidate, Modeling Nature: Cellular Automata Simulations with Mathmatica (Springer-Verlag, New York, 1996), Chap. 1.

4. M. Gardner, "Mathematical Games: The fantastic combinations of John Conway's new solitaire game "life," Scientific American 223, 120-123 (Oct., 1970).

5. Allen J. Wood and Bruce F. Wollenberg, Power Generation, Operation, and Control (John Wiley and Sons, New York, 1996), Chap. 11.

6. Davor Skrec, Slavko Krajcar, and Snjezana Blagajac, "Application of GIS Technology in Electrical Distribution Network Optimization," Online, (http://www.odyssey.ursus.maine.edu/giseb/spatdb/egis/e g94210.himl).

7. Zarko Sumic, "Internet-Abled Outage Management System," Proceedings Transmission and Distribution World Expo 1997, Atlanta, GA.

For more information please contact:

L. Jonathan Dowell, Ph.D.

Los Alamos National Laboratory

Energy and Environmental Analysis Group

P.O. Box 1663, MS F604

Los Alamos, New Mexico 87545

Phone: (505) 665-9193, Fax: (505) 665-5125

E-mail: lidowell@lanl.gov 